\title{
Aspectos éticos da obtenção de dentes por estudantes de uma graduação em Odontologia
}

Elaine Fernandes Felipe ${ }^{1}$, Greise Borges Mezzari da Costa ${ }^{2}$, Nilton Jank Júnior ${ }^{3}$, Jorge Alexandre da Costa ${ }^{4}$

\section{Resumo}

O objetivo do presente trabalho foi avaliar a procedência dos dentes utilizados em uma perspectiva ética e legal pelos alunos do curso de Odontologia da Universidade do Sul de Santa Catarina - Unisul. Foram empregados dois questionários com perguntas relacionadas à temática, um direcionado aos professores e outro aos alunos. Os resultados mostraram que existe comércio ilegal de dentes entre os estudantes do curso de Odontologia, pois $11 \%$ dos discentes entrevistados afirmaram já ter comprado dentes em algum momento de sua vida acadêmica, sendo o fornecedor mais citado o colega de faculdade. 0 trabalho mostrou que são utilizados em torno de 688 dentes por semestre, divididos entre cinco disciplinas pré-laboratoriais; dentre essas, nenhuma relata de maneira formal as implicações éticas e legais do uso de dentes humanos.

Palavras-chave: Dente. Ensino. Bioética. Legislação.

\section{Resumen}

\section{Análisis ético de la obtención de dientes utilizados por estudiantes de una graduación en Odontología}

El objetivo de este estudio fue evaluar los méritos de los dientes utilizados en una perspectiva ética y jurídica para los estudiantes de Odontología de la Universidad del Sur de Santa Catarina - Unisul. Se emplearon dos cuestionarios con preguntas relacionadas con el tema, uno a los profesores y otro a los estudiantes. Los resultados mostraron que existe un comercio ilegal de dientes entre los estudiantes de odontología, ya que el $11 \%$ de los estudiantes encuestados dijeron que ya habían comprado los dientes en algún momento de su vida académica, siendo citada empresa el compañero de la universidad. El estudio mostró que se utilizan alrededor de 688 dientes por semestre, dividido entre cinco disciplinas pre-laboratorio, entre ellos, no hay informes de implicaciones formalmente legales y éticas de la utilización de los dientes humanos.

Palabras-clave: Diente. Enseñanza. Bioética. Legislación.

\section{Abstract \\ Ethical aspects of teeth obtained by odontology graduates}

The objective of this study was to evaluate the merits of the teeth used in an ethical and legal perspective for students of Dentistry, University of Southern Santa Catarina - Unisul. Two questionnaires were employed, one applied to the professors and another to the students with questions concerning the subject. The results showed that there is illegal trade of teeth among students of Dentistry from Unisul, because $11 \%$ of respondents affirmed they had bought teeth at some point in their academic life, in which the most mentioned provider was a college classmate. This work presented that around 688 teeth are used per semester divided into five pre-laboratory disciplines; among these, none reports formally legal and ethical implications of using human teeth.

Key words: Tooth. Teaching. Bioethics. Legislation.

Aprovação CEP 10.078.4.02.III

1. Graduanda elainefernandesfelipe@live.com 2. Graduada greise.costa@unisul.br 3. Graduado nilton.junior@unisul.br 4. Mestre Jorge.costa@unisul.br - Universidade do Sul de Santa Catarina (Unisul), Tubarão/SC, Brasil.

Correspondência

Elaine Fernandes Felipe - Rua Januário Corrêa Bittencourt, 15 CEP 88708-285. Tubarão/SC, Brasil.

Declaram não haver conflito de interesse. 
O dente humano é uma ferramenta didática valiosa nos cursos de Odontologia, pois é por meio dele que os alunos têm o primeiro contato prático com técnicas e materiais em muitas disciplinas pré-clínicas laboratoriais ${ }^{1-6}$. Os discentes sentem-se mais seguros para a prática clínica quando obtêm treinamento prévio em dentes humanos, embora ante questões éticas, legais e de biossegurança aceitem igualmente o treino em dentes de resina ${ }^{4}$.

Também são empregados como fonte dos mais diversos tipos de pesquisa da área odontológica, já que nenhum material é capaz de reproduzir tão bem as características físico-químicas e morfológicas quanto o próprio elemento dental ${ }^{7-9}$. Uma faculdade de Odontologia pode gastar de três a quatro mil dentes por semestre, divididos em atividades de pesquisa e para fins didáticos ${ }^{2}$.

Os dentes, quando manipulados de maneira inadequada, apresentam grande potencial de infecção. É necessário haver um protocolo de desinfecção, esterilização e armazenamento visando o uso seguro do órgão dental ${ }^{3,10,11}$. A Lei 9.434 , de 4 de fevereiro de 1997, que dispõe sobre a remoção de órgãos, tecidos e partes do corpo humano para fins de transplante e tratamento, e sobre outras providências, considera como crime no seu artigo 15 o comércio de órgãos, com pena prevista de três a oito anos de reclusão e multa ${ }^{12}$. 0 artigo 6 diz ser contravenção remover, post-mortem, órgãos, tecidos e partes do corpo humano de pessoas não identificadas. O artigo 210 do Código Penal prevê ainda pena de um a três anos de cárcere para aqueles que violarem sepulturas ${ }^{13}$.

O Código de Ética Odontológica, em seu Capítulo XVII, adverte que constitui infração ética desatender as normas do órgão competente e a legislação sobre pesquisa em saúde ${ }^{14}$. Complementa indicando que também é vedado infringir a legislação que regulamenta a utilização de cadáver para estudo e/ou exercícios de técnicas cirúrgicas, bem como a que regula os transplantes de órgãos e tecidos post-mortem e do "próprio corpo vivo".

A Resolução CNS 466/12 baseia-se em vários documentos internacionais que norteiam a ética em pesquisas envolvendo seres humanos ${ }^{15}$. Com a criação dos comitês de ética em pesquisa, a origem dos dentes usados em análises passou a ter que ser especificada para a aprovação, pois os comitês não autorizam pesquisas que utilizam dentes humanos com origem desconhecida ou ilegal ${ }^{16}$. Esse fato faz com que, obrigatoriamente, os elementos dentais utilizados em pesquisas atualmente estejam de acordo com as exigências legais e éticas, ou seja, es- tejam acompanhados de termo de consentimento livre e esclarecido (TCLE) para doação, e a grande maioria origina-se de bancos de dentes humanos ${ }^{8-9}$.

Porém, os dentes usados pelos alunos de graduação na maioria das instituições de ensino não têm origem legal ${ }^{3,5,6}$. Ainda é pequeno o número de bancos de dentes humanos nas faculdades brasileiras. A maioria dos professores simplesmente entrega a lista dos elementos dentários necessários para a disciplina, cabendo ao aluno obter os dentes ${ }^{5}$. Como grande parcela dos estudantes não recebe orientações sobre as implicações éticas e legais da aquisição de órgãos dentais e os professores não questionam a origem desses elementos, os discentes acabam obtendo dentes de forma ilícita e não ética, geralmente adquirindo-os em cemitérios, clínicas particulares e até mesmo de colegas, mantendo o tráfico de material humano ${ }^{1-6,17}$.

\section{Material e método}

Este trabalho foi avaliado e aprovado pelo comitê de ética em pesquisa (CEP/Unisul) e todos os sujeitos pesquisados autorizaram sua participação na investigação mediante leitura e assinatura do TCLE. Os dados foram coletados a partir de dois questionários com questões fechadas: um voltado para os alunos de graduação e outro dirigido aos professores responsáveis pelas disciplinas do curso de Odontologia da Unisul. Foram convidados a participar do estudo os 45 docentes responsáveis pelas disciplinas do curso citado, bem como os 182 alunos matriculados, sendo que, quando um discente cursava disciplinas de diferentes fases, considerou-se o semestre menos adiantado.

Após a apresentação pormenorizada do trabaIho, na qual foram abordados o assunto, objetivo, metodologia, riscos e os cuidados tomados para a preservação do anonimato e o esclarecimento de qualquer eventual dúvida a respeito da pesquisa, os sujeitos receberam o questionário e o TCLE. Os documentos foram recolhidos em urnas separadas, garantindo o anonimato dos participantes.

Após as aplicações dos questionários os resultados foram tabulados e submetidos à análise estatística descritiva. O número de dentes utilizados por semestre foi calculado multiplicando o número médio das turmas (20 alunos) pela quantidade média de elementos dentários solicitados ao aluno por disciplina. A aplicação do questionário ocorreu dez dias antes do encerramento do segundo semestre letivo de 2010 . 


\section{Resultados}

Participaram da pesquisa 182 alunos matriculados entre o primeiro e o nono semestre. A distribuição dos estudantes por fase se encontra no Quadro 1. Entre os discentes pesquisados, $89 \%$ relataram nunca ter comprado dentes, sendo que estes foram obtidos a partir de concessões. A doação por dentista conhecido foi citada por $72 \%$ dos estudantes participantes, $35 \%$ receberam órgãos dentários de colega de faculdade, $20 \%$ conseguiram os elementos junto a postos de saúde, $17 \%$ em clínicas populares e $15 \%$ obtiveram os dentes em cemitérios.

Entre os alunos pesquisados, $11 \%$ declararam já ter comprado dentes humanos. A compra de elementos dentários de colega de faculdade foi apontada por $4,7 \%$ dos alunos, como cemitérios $(2,1 \%)$, técnico em prótese dentária $(1,5 \%)$, dentista conhecido $(1,2 \%)$, clínicas populares $(1 \%)$ e dentista ilegal (0,5\%).

A descontaminação do elemento dental foi relatada por $63,2 \%$ dos alunos pesquisados, sendo a imersão em diferentes soluções de hipoclorito de sódio a mais citada (22,5\%). A submersão em água oxigenada foi mencionada por $19,8 \%$ e a imersão em álcool a $70^{\circ}$ foi apontada por $17 \%$ dos discentes consultados. Também foram relatados lavagem com água e sabão (11\%), fervura em água (10\%), submersão em água com bicarbonato de sódio (9\%), exposição à luz solar $(5,7 \%)$ e esterilização em autoclave (5\%).

Embora $19,2 \%$ do total de participantes tenham declarado receber alguma orientação sobre as implicações éticas e legais da obtenção e uso do elemento dental, esse número variou entre $0 \%$ dos alunos do primeiro semestre e $93 \%$ dos alunos da nona fase, conforme o Quadro 1.

Participaram deste estudo 41 disciplinas representadas pelos seus docentes responsáveis. Dentre as matérias pesquisadas, cinco $(12,2 \%)$ solicitam dentes humanos para as atividades em laboratório. O número de elementos solicitados, conforme indicado no Quadro 2, varia de 2 a 14. Todas as disciplinas que solicitam órgãos dentários aos estudantes declararam orientá-los a respeito das questões éticas e legais envolvidas; porém, tais informações são passadas de maneira informal. Os discentes são ainda instruídos a buscar os elementos junto ao banco de dentes humanos, prefeituras, clínica da faculdade e profissionais conhecidos.

Dentre as disciplinas pesquisadas que não solicitam dentes humanos, cinco declararam também orientar os alunos sobre as questões éticas e legais envolvidas no uso de elementos dentários, mas essa orientação acontece de maneira informal. Somente em uma delas os alunos recebem informação curricular em sala de aula a respeito das implicações éticas e legais envolvidas.

Quadro 1. Distribuição de alunos por semestre e índice de alunos que receberam orientações éticas e legais a respeito do uso de dentes extraídos

\begin{tabular}{|c|c|c|}
\hline Semestre & $\begin{array}{c}\mathbf{N}^{\circ} \text { de } \\
\text { alunos }\end{array}$ & $\begin{array}{c}\text { \% que recebeu orientação } \\
\text { ético-legal sobre o uso de } \\
\text { dentes humanos }\end{array}$ \\
\hline 1 & 15 & $0 \%$ \\
\hline 2 & 22 & $9 \%$ \\
\hline 3 & 14 & $14 \%$ \\
\hline 4 & 28 & $25 \%$ \\
\hline 5 & 20 & $30 \%$ \\
\hline 6 & 27 & $63 \%$ \\
\hline 7 & 14 & $29 \%$ \\
\hline 8 & 28 & $11 \%$ \\
\hline 9 & 14 & $93 \%$ \\
\hline $\begin{array}{c}\text { Total } \\
\text { (média) }\end{array}$ & $\begin{array}{c}182 \\
(20,22)\end{array}$ & $19,2 \%$ \\
\hline
\end{tabular}

Fonte: elaborado pelos autores, 2013.

Quadro 2. Número de dentes solicitados por disciplina e número utilizado por semestre

\begin{tabular}{|c|c|c|}
\hline Disciplina & $\begin{array}{c}\mathbf{N}^{\circ} \text { de dentes } \\
\text { solicitados por } \\
\text { aluno }\end{array}$ & $\begin{array}{c}\text { Dentes utilizados } \\
\text { por semestre }\end{array}$ \\
\hline A & 2 & 40,44 \\
\hline B & 3 & 60,66 \\
\hline C & 4 & 80,88 \\
\hline D & 11 & 222,42 \\
\hline E & 14 & 283,08 \\
\hline \multicolumn{2}{|c|}{ Total } & 687,48 \\
\hline
\end{tabular}

Fonte: elaborado pelos autores, 2013.

\section{Discussão}

O uso de dentes naturais ainda é uma realidade nas disciplinas laboratoriais. Embora esta pesquisa não tenha explorado a razão da utilização dos elementos dentários, estudos indicam que nenhum modelo artificial é capaz de reproduzir com tanta fidelidade as características do elemento dental ${ }^{7-9,18}$, 
somada ao fato pertinente de que o treinamento em dentes naturais deixa o aluno mais confiante para a prática em pacientes ${ }^{4}$.

Conforme os resultados deste trabalho, podemos estimar que sejam utilizados aproximadamente 688 dentes por semestre nas disciplinas laboratoriais da universidade em questão. Carvalho ${ }^{2}$ estimou que uma faculdade de Odontologia utiliza em torno de 3.000-4.000 elementos dentários por semestre entre atividades de pesquisa e ensino. Tal diferença nos resultados deve-se ao fato de que, neste estudo, não foram contados os dentes utilizados na realização de pesquisas. $\mathrm{O}$ comércio de dentes ainda é uma realidade nos corredores da faculdade de Odontologia da Unisul, pois foi relatado por $11 \%$ dos alunos entrevistados. Trabalhos anteriores já apontavam a existência da venda de órgãos dentários entre os acadêmicos do curso de Odontologia, com índices que variam entre $1,2 \%$ em publicação recente ${ }^{6}$ e $40 \%$ $70 \%$ em publicações mais antigas ${ }^{3,5}$. A conscientização dos alunos, bem como a estruturação de Bancos de Dentes Humanos, parece ter contribuído para a diminuição do comércio de elementos dentários.

Com exceção dos alunos do sexto e nono semestres, que afirmaram ter recebido orientações a respeito das implicações éticas e legais do uso de dentes humanos, representando, respectivamente, $63 \%$ e $93 \%$ dos entrevistados, em nenhuma outra turma o índice ficou acima dos 50\%, embora este assunto tenha sido abordado por onze $(27 \%)$ das disciplinas entrevistadas. Contudo, na maioria das vezes de maneira informal. Em apenas uma disciplina, sem prática clínica, o assunto é tratado de maneira formal e voltado quase que exclusivamente para os aspectos éticos-legais em Odontologia.

A conscientização do aluno de Odontologia sobre as implicações éticas e legais que envolvem o uso de dentes humanos deve ocorrer de modo formal e gradativo durante o desenvolvimento na graduação. Dessa forma, no momento em que forem solicitados elementos dentários naturais, o aluno terá formação teórica para não cometer infrações éticas e descumprir a legislação brasileira. Aliar a Odontologia Legal ao fortalecimento dos Bancos de Dentes Humanos é a melhor maneira de adequar o uso de elementos dentários necessários para a formação profissional, dentro das exigências éticas e legais, além de proporcionar o uso biologicamente mais seguro de dentes.

Além de todo o aprendizado técnico, o aluno de Odontologia deve também ser apresentado a todas as questões éticas, culturais e sociais envolvidas no exercício de sua profissão. O cirurgião-dentista trata de pessoas e não simplesmente de dentes. Contudo, conforme trabalho publicado por Amorim e colaboradores ${ }^{19}$, o ensino de Odontologia na graduação no Brasil é predominantemente técnico e curativo.

O uso de dentes humanos pelos alunos de graduação de Odontologia representa mais uma face da complexa realidade social e cultural brasileira, pois os cidadãos das classes sociais menos favorecidas têm menor acesso à informação e aos avanços técnicos da odontologia, além de desconhecerem o valor do órgão dental, estando, portanto, mais vulneráveis a práticas mutiladoras e a doação ilegal do dente ${ }^{15}$. Assim, quantidade expressiva dos dentes utilizados no ensino da Odontologia provém de pessoas socialmente desfavorecidas ${ }^{20-21}$, frutos de um círculo social vicioso. Cabe aos profissionais envolvidos estar atentos a esses fatores no devido processo de obtenção do consentimento, buscando evitar a exploração e a violação da dignidade dos doadores de dentes.

\section{Considerações finais}

Os resultados deste estudo revelam a existência do comércio de dentes entre os alunos de um curso de graduação em Odontologia de uma universidade do Brasil. Revelam, também, que os professores não exigem a certificação da procedência dos dentes, de modo que a maioria dos elementos utilizados não atende as exigências éticas, legais e de biossegurança para a utilização de órgãos humanos. Além disso, segundo a maioria dos estudantes consultados, a informação a respeito das implicações éticas e legais do uso de dentes humanos ocorre formalmente apenas no nono semestre da graduação, quando é ministrada disciplina que aborda exclusivamente o tema.

É indubitável que o conhecimento das implicações éticas e legais a respeito da utilização de órgãos humanos nas práticas de aprendizado é componente fundamental para a conscientização dos alunos participantes de disciplinas laboratoriais que utilizam dentes humanos em atividades pré-clínicas. Por isso, é necessário que as informações e reflexões éticas sobre o assunto sejam abordadas desde os primeiros semestres do curso, antes que os alunos ingressem nas disciplinas laboratoriais.

Em paralelo, a capacitação dos docentes responsáveis por disciplina laboratorial quanto à necessidade de certificação de procedência dos dentes também é fundamental para a redução do 
uso de dentes indevidamente obtidos. Finalmente, a criação e o fortalecimento dos bancos de dentes humanos também contribuiriam para que alunos e professores tenham acesso a dentes que atendam às exigências éticas e legais, vez que são funções do banco de dentes a coleta e distribuição de dentes humanos dentro de padrões éticos, legais e de biossegurança.

\section{Referências}

1. Ramos DLP, Trindade OM. Ética na pesquisa odontológica com seres humanos. In: Silva M, Cavielli ITP, organizadores. Compêndio de odontologia legal. Rio de Janeiro: Guanabara Koogan; 1997. p. 89-90.

2. Carvalho C. Dentes na mira da ética. Rev Odontol Bras. 2001;58(2):108-11.

3. Paula S, Bittencourt LP, Pimentel E, Gabrieli Filho PA, Imparato JCP. Comercialização de dentes nas universidades. Pesqui Bras Odontoped Clín Integr. 2001;1(3):38-41.

4. Brasil AS, Ana PA, Botta SB, Franchim GH, Imparato JCP. Uso de dentes humanos no ensino laboratorial, meios de aquisição e desinfecção pelos alunos de graduação da Fousp-SP. 19a Reunião da Sociedade Brasileira de Pesquisa Odontológica; 2002. Pesqui Odontol Bras. 2002;16(suppl):31.

5. Nassif ACS, Tieri F, Ana PA, Botta SB, Imparato JCP. Estruturação de um banco de dentes humanos. Pesqui Odontol Bras. 2003;17(1):70-4.

6. Costa SM, Mameluque S, Brandão EL, Melo AEMA, Pires CPAB, Rezende EJC et al. Dentes humanos no ensino odontológico: procedência, utilização, descontaminação, e armazenamento pelos acadêmicos da Unimontes. Revista da Abeno. 2007;7(1):7-12.

7. Busato ALS, Konzen V. Coroa total com dente natural. RGO. 1991;38(3):195-8.

8. Franchim GH, Brasil AS, Ana PA, Botta SB, Tieri F, Matsumoto IT. Uso de dentes nas pesquisas das $17^{\mathrm{a}}$ e $18^{\mathrm{a}}$ reuniões anuais da SBPqO. Pesq Odontol Bras. 2002;16(suppl):235.

9. Silva SR. Mais ética nas pesquisas. Revista da APCD. 2001;55(6):393-7.

10. Pantera EA Jr, Schuster GS. Sterilization of extracted human teeth. J Dent Educ. 1990;54(5):283-5.

11. Crawford JJ. State-of-the-art: practical infection control in dentistry. J Am Dent Assoc. 1985;110(4):629-33.

12. Brasil. Lei $n^{\circ} 9.434$, de 4 de fevereiro de 1997 . Legislação brasileira sobre doação de órgãos humanos e de sangue. $2^{\mathrm{a}}$ ed. Brasília: Câmara dos Deputados; 2009.

13. Brasil. Código Penal. $6^{\mathrm{a}}$ ed. Porto Alegre: Departamento de Artes Gráficas; 2013.

14. Conselho Federal de Odontologia. Código de ética odontológica: aprovado pela Resolução CFO $n^{\circ}$ 118/2012. [Internet]. (acesso 18 out. 2013). Disponível: http://cfo.org.br/wp-content/ uploads/2009/09/codigo_etica.pdf

15. Conselho Nacional de Saúde (Brasil). Resolução $n^{\circ} 466$, de 12 de dezembro de 2012. Aprovar as diretrizes e normas regulamentadoras de pesquisas envolvendo seres humanos. [Internet]. 2012 (acesso 18 out. 2013). Disponível: http://conselho.saude.gov.br/resolucoes/2012/Reso466.pdf

16. Ferreira EL, Fariniuk LF, Cavali AEC, Baratto Filho F, Ambrósio AR. Banco de dentes: ética e legalidade no ensino, pesquisa e tratamento odontológico. Rev Bras Odontol. 2003;60(2):120-2.

17. Zucco D, Kobe R, Fabre C, Madeira L, Baratto Filho F. Avaliação do nível de conhecimento dos acadêmicos do curso de odontologia da Univille sobre a utilização de dentes extraídos na graduação e banco de dentes. RSBO (Impr.). 2006;3(1):54-8.

18. Gomes G, Gomes G, Pupo Y, Gomes O, Schmidt L, Kozlowski V. Utilização de dentes humanos: aspectos éticos e legais. RGO. 2013;61(0):477-83.

19. Amorim KPC, Germano RM, Avelino ANO, Costa ICC. Mutilações dentárias: os dilemas da prática na visão de docentes universitários. Rev. bioét. (Impr.). 2009;17(1):109-21.

20. Cimões R, Caldas Júnior AF, Souza EHA, Gusmão ES. Influência da classe social nas razões clínicas das perdas dentárias. Ciênc Saúde Coletiva. 2007;12(6):1.691-7.

21. Poletto MM, Moreira M, Dias MM, Lopes MGK, Lavoranti OJ, Pizzato E. Banco de dentes humanos: perfil sociocultural de um grupo de doadores. RGO. 2010;58(1):91-4.

\section{Participação dos autores}

Elaine Fernandes Felipe: redação do artigo e revisão crítica, aprovação da versão a ser publicada. Greise Borges Mezzari da Costa: revisão bibliográfica, coleta de dados, análise e interpretação dos dados. Nilton Jank Júnior: revisão bibliográfica e tabulação dos dados. Jorge Alexandre da Costa: coleta de dados, redação do artigo, revisão crítica e aprovação da versão a ser publicada.

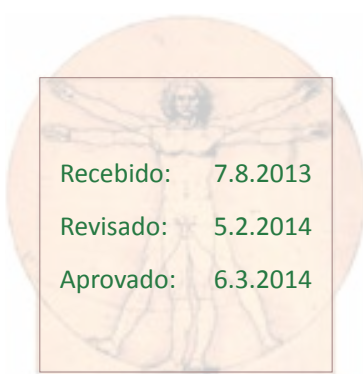

